\title{
Validação interlaboratorial do teste de polarização fluorescente para o diagnóstico sorológico da brucelose bovina
}

\author{
Interlaboratorial validation of the fluorescence polarization assay for the \\ serodiagnosis of bovine brucellosis
}

\section{Luis Antonio Mathias ${ }^{\mathrm{I}}$ Luis Gustavo Corbellini ${ }^{\mathrm{II}}$ Lúcia Maia' ${ }^{\mathrm{III}}$ Kelly Fagundes Nascimento ${ }^{\mathrm{III}}$ Lília Márcia Silva Paulin ${ }^{\text {IV }}$ Luis Ernesto Samartino ${ }^{\mathrm{V}}$ Marco Antonio Serqueira ${ }^{\mathrm{II}}$ Paulo Martins Soares Filho"II Marcília Maria Alves de Souza ${ }^{\text {III }}$}

\section{RESUMO}

Esta investigação teve por objetivo validar o teste de polarização fluorescente (TPF) para o diagnóstico sorológico da brucelose bovina, determinando a sensibilidade (SE) e a especificidade relativas $(S P) e$ verificando a reprodutibilidade do teste em quatro laboratórios no Brasil. Foram selecionadas 1.389 amostras de soro sanguíneo, as quais foram inicialmente submetidas aos testes do antígeno acidificado tamponado (AAT) e mercaptoetanol (2-ME). As mesmas amostras foram submetidas à reação de fixação de complemento (RFC) $e$ ao TPF. Para a avaliação do TPF, foi adotada a combinação dos resultados do AAT, da RFC e do 2-ME, utilizados como população de referência (padrão-ouro). Para a determinação do ponto de corte do TPF que proporciona a melhor combinação de sensibilidade e especificidade, foi usada a análise TG-ROC. A concordância entre os resultados dos quatro laboratórios foi determinada com base no indicador kappa e no coeficiente de correlação de Pearson. Os pontos de corte do TPF situaram-se entre 85,2 e 93,6 $m P$, conforme o laboratório. A sensibilidade variou de 91,7 a 97,3\%, e a especificidade situou-se na faixa de 82,6 a 98,3\%. Na comparação entre os resultados do TPF dos quatro laboratórios, o indicador kappa ficou entre 0,69e 0,95, o que indica, na maioria das situações, reprodutibilidade excelente, e o coeficiente de correlação variou entre 0,76 e 0,99. Os resultados indicaram que o TPF apresentou bom desempenho, na maioria das situações, com sensibilidade e especificidade elevadas. Em comparação com os testes convencionais, o TPF apresenta as vantagens de ser de execução mais rápida e mais fácil e não estar sujeito à ocorrência de prozona, como a RFC e o 2-ME, nem de atividade anticomplementar, como a RFC.

Palavras-chave: brucelose bovina, diagnóstico sorológico, teste de polarização fluorescente.

\begin{abstract}
The purpose of this research was the interlaboratorial validation of the polarization fluorescence assay (PFA) for the serodiagnosis of bovine brucellosis, verifying the relative sensitivity, the relative specificity and the reproducibility of the test in four Brazilian laboratories. Serum samples from 1,389 bovines were selected and submitted to the rose Bengal (RBT) and 2-mercaptoethanol tests in one of the laboratories. The same samples were tested by the complement fixation (CFT) test and by the PFA in the four laboratories participating of the research. The reference population (golden standard) used to evaluate the PFA was the combination of the results of RBT, CFT and 2-ME. TGROC analysis was used to obtain the cut-off that provided the best combination of sensitivity and specificity. The agreement between laboratories was obtained by the kappa statistic and Pearson correlation coefficient ( $r$ ). The PFA cut-off values were from 85.2 to 93.6. The sensitivity of the PFA assay varied from $91.7 \%$ to $97.3 \%$, and the specificity values varied from $82.6 \%$ to $98.3 \%$. When comparing PFA results from the four laboratories, the kappa values was between 0.69 and 0.95 , which indicates, in most situations, excellent reproducibility, and the correlation coefficient varied from 0.76 to 0.99 . The results showed that the PFA had a good performance, with high sensitivity and specificity. Compared to the conventional
\end{abstract}

'Departamento de Medicina Veterinária Preventiva e Reprodução Animal, Faculdade de Ciências Agrárias e Veterinárias (FCAV), Universidade Estadual Paulista (Unesp). Via de Acesso Prof. Paulo D. Castellane, Km 5, 14884-900, Jaboticabal, SP, Brasil. Email: 1mathias@fcav.unesp.br. Autor para correspondência.

"Laboratório de Epidemiologia Veterinária (EpiLab), Universidade Federal do Rio Grande do Sul (UFRGS), Porto Alegre, RS, Brasil.

"IIMinistério da Agricultura, Pecuária e Abastecimento, Brasília, DF, Brasil.

${ }^{\mathrm{IV}}$ Instituto Biológico de São Paulo, São Paulo, SP, Brasil.

${ }^{\vee}$ Instituto Nacional de Tecnologia Agropecuária (INTA), Buenos Aires, Argentina. 
tests, the PFA has the advantages of being easy and quick to perform, and it is not prone to the occurrence of prozone, as the CFT or the 2-ME, nor to the occurrence of anticomplementary effect, as the CFT.

Key words: bovine brucellosis, serological diagnosis, fluorescence polarization assay.

\section{INTRODUÇÃO}

A importância do diagnóstico sorológico nos programas de controle e erradicação da brucelose bovina incentivou o desenvolvimento de um grande número de testes voltados para essa finalidade. Desse grande número de testes disponíveis, o Programa Nacional de Controle e Erradicação de Brucelose e Tuberculose (PNCEBT) optou pelo uso do teste do antígeno acidificado tamponado (AAT) para triagem, sendo a confirmação dos resultados positivos efetuada pela combinação do teste de soroaglutinação lenta em tubos (SAL) com o teste do 2-mercaptoetanol (2-ME) ou pela reação de fixação de complemento (RFC) (BRASIL, 2004). Esse protocolo de triagem e teste confirmatório em série apresenta sensibilidade e especificidade estimadas de 95 e 99,5\%, respectivamente (GONÇALVES et al., 2009).

Os testes adotados pelo programa brasileiro apresentam a vantagem de serem de baixo custo, o que permite uma aplicação mais ampla, porém apresentam também desvantagens. A combinação dos testes de SAL e 2-ME tem como desvantagens: longo tempo para a obtenção do resultado (48 horas); gasto de grande quantidade de reagentes, ocupando grandes espaços quando são testadas muitas amostras; uso de substância tóxica; e necessidade de as amostras de soro estarem em condições ótimas de conservação. As principais desvantagens da RFC são: técnica bastante trabalhosa, que exige equipes altamente treinadas para a obtenção de um resultado confiável; uso de reagentes lábeis que precisam ser constantemente preparados e titulados; ocorrência de atividade anticomplementar, principalmente em amostras mal- conservadas; e ocorrência de efeito prozona, que pode levar à obtenção de resultados falso-negativos; a maioria desses fatores pode comprometer a precisão (reprodutibilidade e repetibilidade) da RFC (CHAPPEL, 1989).

Considerando essas desvantagens, outras opções podem ser adotadas por um programa, entre elas, o teste de polarização fluorescente (TPF). Esse teste baseia-se na diferença rotacional entre a molécula de antígeno solúvel (marcado com fluorocromo) e essa mesma molécula ligada ao anticorpo. Uma molécula menor gira aleatoriamente a uma velocidade maior, resultando em rápida despolarização da luz, ao passo que um complexo maior gira mais lentamente, e a despolarização da luz ocorre a uma taxa mais reduzida. Essa mudança na despolarização da luz é detectada por um analisador de polarização fluorescente (NIELSEN \& GALL, 2001).

O primeiro trabalho aplicando essa técnica ao diagnóstico da brucelose bovina foi desenvolvido por NIELSEN et al. (1996). Esses autores relataram que a análise de 8.669 soros de rebanhos canadenses livres de brucelose resultou em uma especificidade de $99,96 \%$, e o teste de 561 soros de animais dos quais havia sido isolada Brucella abortus apontou uma sensibilidade de $99,02 \%$. Os autores testaram ainda 250 soros de animais vacinados com a amostra B $19 \mathrm{e}$ obtiveram uma especificidade de 99,2\%. Esses resultados mostraram a capacidade do teste de combinar elevada sensibilidade com elevada especificidade e mostraram ainda que a especificidade do teste é elevada mesmo quando usado para testar soros de animais vacinados.

Em outra investigação, testando soros de diversas procedências (Argentina, Chile, México e Estados Unidos), NIELSEN et al. (1998) verificaram sensibilidade variando de 87,5 a $100,0 \%$ e especificidade de 94,9 a $100,0 \%$. Observaram ainda que $88,2 \%$ dos animais vacinados com amostra B 19 e positivos em pelo menos um teste convencional tiveram resultado negativo noTPF. Pesquisa realizada na Argentina e envolvendo 733 animais de rebanhos sem evidência de infecção apontou especificidade de $99,6 \%$, enquanto a análise do soro de 1.039 animais de rebanhos infectados revelou sensibilidade de $98,1 \%$. Em animais vacinados com a amostra B 19 de $\boldsymbol{B}$. abortus, foi observada especificidade variando de 64,9\%, aos 26 dias após a vacinação, a 97,1\%, após 272 dias de vacinação (SAMARTINO et al., 1999). Avaliando o TPF no México, DAJER et al. (1999) observaram sensibilidade relativa de $99,0 \%$ e especificidade relativa de $96,9 \%$.

McGIVEN et al. (2003) avaliaram o TPF em 146 amostras de soros de bovinos com isolamento de Brucella abortus, obtidos em vários países europeus, e em 1.947 amostras de soros de rebanhos britânicos livres de brucelose. Constataram sensibilidade de $96,6 \%$ e especificidade de $99,1 \%$. Esses autores observaram que o TPF foi o que apresentou maior valor quando somadas a sensibilidade e a especificidade de cada teste, em comparação com Elisa indireto, Elisa competitivo, RFC e soroaglutinação.

Por tratar-se de um teste ainda não utilizado no Brasil, esta investigação teve por objetivo validar o TPF, determinando a sensibilidade (SE) e a 
especificidade relativas (SP) e verificando a reprodutibilidade do teste em quatro laboratórios.

\section{MATERIAL E MÉTODOS}

Os testes foram executados em quatro laboratórios de instituições públicas, aqui denominados de 1, 2, 3 e 4, sendo dois localizados no Estado de São Paulo, um no Estado de Minas Gerais e um no Estado de Pernambuco.

Considerando que todos os laboratórios testaram as mesmas amostras de soro, os testes do AAT e do 2-ME foram realizados apenas no laboratório 1, em decorrência da limitação no volume de soro disponível. Já os testes de fixação de complemento e de polarização fluorescente foram realizados nos quatro laboratórios.

A população de referência (padrão-ouro) foi obtida pela combinação dos resultados de AAT, RFC e 2-ME. Animais com resultado positivo nesses três testes foram considerados infectados; animais com resultado negativo nos três testes foram considerados não infectados; e animais com resultados divergentes entre esses testes foram excluídos da análise.

Os testes AAT e 2-ME foram executados conforme descrito no Manual Técnico do Programa Nacional de Controle e Erradicação de Brucelose e Tuberculose - PNCEBT (BRASIL, 2006) e interpretados conforme prevê o Regulamento Técnico do PNCEBT (BRASIL, 2004). Foram selecionadas 1.389 amostras de soro sanguíneo de bovinos com resultados concordantes entre os testes AAT e 2-ME. Essas amostras foram divididas em quatro alíquotas, que foram encaminhadas aos quatro laboratórios participantes do estudo.

Para a RFC, foi adotada a microtécnica descrita por ALTON et al. (1988), com incubação a $37^{\circ} \mathrm{C}$ por 30 minutos, nas duas fases da reação, sendo utilizado o mesmo antígeno usado no teste de SAL. O título foi obtido pela recíproca da maior diluição do soro com pelo menos $25 \%$ de fixação de complemento, sendo considerado positivo o soro com pelo menos $25 \%$ de fixação de complemento na diluição $1: 4$ (ALTON et al., 1988).

O TPF foi realizado com o "Brucella abortus Antibody Test Kit" produzido por Diachemix, USA, composto por soro controle-positivo, soro controle-negativo, tampão concentrado 25 vezes e antígeno lipopolissacarídeo conjugado com fluoresceína. Testaram-se os soros na diluição 1:100, com $10 \mu \mathrm{L}$ de soro e $990 \mu \mathrm{L}$ de diluente. Após pelo menos cinco minutos da diluição, agitaram-se os soros em agitador de tubos, e realizou-se uma primeira leitura.
Em seguida, acrescentaram-se $10 \mu \mathrm{L}$ de conjugado, agitou-se novamente o tubo e, após pelo menos dois minutos, realizou-se a segunda leitura. As leituras foram feitas usando um analisador de polarização fluorescente modelo Sentry 100 (Diachemix, USA), sendo os resultados expressos em unidades de milipolarização (mP).

Para a determinação do ponto de corte (PC), foi utilizada a técnica two-graph-receiver operation characteristic (TG-ROC). Essa técnica é derivada da curva ROC e tem a vantagem de as medidas de acurácia poderem ser lidas diretamente do gráfico (GREINER et al., 1995).

Os valores de $\mathrm{mP}$ referentes aos soros testados foram agrupados em classes com intervalo de $2 \mathrm{mP}$ cada. Em cada intervalo de classe, a frequência absoluta, relativa e cumulada de infectados e não infectados foi determinada. O valor da SE foi obtido do complemento (q) da frequência cumulada de animais classificados como infectados em cada classe de $\mathrm{mP}$; e o valor da SP, da frequência cumulada dos animais classificados como não infectados em cada intervalo de classe. Por meio da soma dos valores de SE e SP (DOHOO et al., 2003), pôde-se determinar o PC em mP que maximizava os parâmetros, correspondendo à intersecção da curva TG-ROC; os valores médios de $\mathrm{mP}$ encontrados nas intersecções das curvas de cada laboratório foram usados para dicotomizar as medidas em positivas e negativas. Os resultados foram, então, agrupados em tabelas $2 \times 2$, e a SE determinada dividindo-se o número de resultados positivos no TPF observado entre os animais classificados como infectados pelo número total de animais classificados como infectados; a SP foi obtida dividindo-se o número de resultados negativos no TPF observado entre os animais classificados como não infectados pelo número total de animais classificados como não infectados.

Para as análises comparativas entre os laboratórios, foram usados dados pareados de 939 amostras, que correspondiam aos mesmos animais testados nos quatro laboratórios.

A reprodutibilidade significa a fidelidade dos resultados obtidos por operadores diferentes, sendo utilizados os mesmos métodos e as mesmas amostras. A concordância foi medida com os resultados dicotomizados e contínuos (i.e., em mP) do TPF. Para verificar as concordâncias do TPF em diferentes condições, os resultados dicotomizados dos laboratórios foram avaliados por meio do índice kappa, o qual foi calculado e interpretado segundo LANDIS $\& \operatorname{KOCK}(1977): 0-0,20=$ ruim; $0,21-0,40=$ fraca; 0,41 $-0,60=$ média; $0,61-0,80=$ boa; e $0,81-1=$ excelente. A concordância dos resultados medidos em mP entre 
os laboratórios foi verificada por meio do coeficiente de correlação de Pearson (r). Os testes de concordância foram realizados utilizando o software SPSS.

\section{RESULTADOS E DISCUSSÃO}

Os PCs que maximizavam os valores de $\mathrm{SE}$ e SP encontrados na curva TG-ROC foram 85,2, 93,6, 87,3 e $88,9 \mathrm{mP}$ nos laboratórios 1, 2, 3 e 4, respectivamente. Essa faixa está próxima da observada em outros trabalhos, como, por exemplo, o de NIELSEN et al. (1996), que adotaram um PC de $90 \mathrm{mP}$, o de SAMARTINO et al. (1999), que adotaram $87 \mathrm{mP}$ como PC, e o de DAJER et al. (1999), que concluíram por um PC de 89,9 mP, em trabalho realizado no México. É importante considerar que a variação encontrada entre os PCs observados nos quatro laboratórios, embora pequena, pode ter sido influenciada pelas variações do dia-a-dia no ambiente de teste, fato não levado em consideração pela análise de curva ROC. De acordo com NIELSEN \& GALL (2001), essas variações no diaa-dia podem ser contornadas pelo estabelecimento de um ponto de corte obtido a partir do valor de $\mathrm{mP}$ de um controle negativo.

A SE encontrada foi de 91,7, 97,3, 97,3 e $95,2 \%$, respectivamente, nos laboratórios 1, 2, 3 e 4 (Tabela 1). Esses valores situam-se ligeiramente abaixo da SE observada por NIELSEN et al. (1996), de 99,02\%, em animais dos quais foi isolada B. abortus, por SAMARTINO et al. (1999), de 98,1\%, em animais de rebanhos argentinos dos quais a B. abortus foi isolada de pelo menos um animal, situando-se mais próximos do valor de SE observado no Reino Unido por McGIVEN et al. (2003), de 96,6\%. Os valores de SE observados no presente trabalho também estiveram ligeiramente abaixo do observado por DAJER et al. (1999), 99,0\%, os quais usaram os resultados da RFC como padrão-ouro.

A SP do TPF foi 82,6, 98,3, 98,2 e 98,0\% nos laboratórios 1, 2, 3 e 4, respectivamente (Tabela 1). Os valores observados no presente trabalho, exceto aquele do laboratório 1, encontram-se próximos daqueles verificados em pesquisas realizadas no Canadá, 99,96\% (NIELSEN et al., 1996), na Argentina, 99,6\% (SAMARTINO et al., 1999), e no Reino Unido, 99,1\% (McGIVEN et al., 2003), estando os valores observados em três dos laboratórios ligeiramente acima daquele observado no México por DAJER et al. (1999), de $96,9 \%$, cujo critério para estabelecer a condição verdadeira do animal examinado foi mais próximo do usado no presente trabalho, pois baseou-se nos resultados da RFC.

Trabalhos de pesquisa têm mostrado que $o$ TPF apresenta desempenho superior ao dos testes sorológicos convencionais. McGIVEN et al. (2003) compararam a soma dos percentuais de sensibilidade e especificidade de vários testes usados no diagnóstico sorológico da brucelose bovina e observaram os valores 191,7 para fixação de complemento, 180,4 para soroaglutinação, 195,0 para Elisa indireto, 194,9 para Elisa competitivo 195,7 para o TPF, ou seja, o TPF apresentou a maior soma de percentuais de sensibilidade e especificidade. No presente trabalho, os valores observados para esse parâmetro foram de 174,3, 195,6, 195,5 e 193,2, respectivamente, nos laboratórios 1, 2, 3 e 4 . Por esses dados, pode-se constatar que as somas dos percentuais de sensibilidade e especificidade obtidas para o TPF estão bastante próximas das observadas por aqueles autores para os testes imunoenzimáticos e para TPF; e superiores às observadas para RFC e

Tabela 1 - Sensibilidade (SE) e especificidade (SP) rel ati vas do teste de polari zação fluorescente (TPF), utilizando os pontos de corte médios encontrados na análise TG-ROC de cada laboratório para classificar os animais como positi vos ou negativos, em 939 amostras pareadas.

\begin{tabular}{|c|c|c|c|c|}
\hline Laboratórios & $\begin{array}{c}\text { Infect ados }(\mathrm{n}=336) \\
\text { Pos itivos TPF }\end{array}$ & $\begin{array}{c}\text { Não infectad os }(\mathrm{n}=603) \\
\text { Negativos TPF }\end{array}$ & SE (IC 95\%) & SP (IC 95\%) \\
\hline 1 & 308 & 498 & $\begin{array}{c}91,7 \% \\
(88,7 \%-94,6 \%)\end{array}$ & $\begin{array}{c}82,6 \% \\
(79,6 \%-85,6 \%)\end{array}$ \\
\hline 2 & 327 & 593 & $\begin{array}{c}97,3 \% \\
(95,6 \%-99,1 \%)\end{array}$ & $\begin{array}{c}98,3 \% \\
(97,3 \%-99,4 \%)\end{array}$ \\
\hline 3 & 327 & 592 & $\begin{array}{c}97,3 \% \\
(95,6 \%-99,1 \%)\end{array}$ & $\begin{array}{c}98,2 \% \\
(97,1 \%-99,2 \%)\end{array}$ \\
\hline 4 & 320 & 591 & $\begin{array}{c}95,2 \% \\
(93,0 \%-97,5 \%)\end{array}$ & $\begin{array}{c}98,0 \% \\
(96,9 \%-99,1 \%)\end{array}$ \\
\hline
\end{tabular}

IC $=$ intervalo de confiança 
soroaglutinação, confirmando o desempenho superior do TPF em relação a testes convencionais como soroaglutinação e fixação de complemento.

$\mathrm{Na}$ comparação dos resultados da presente pesquisa com aqueles constatados por outros autores, é importante salientar que o uso dos testes sorológicos convencionais para estabelecer a condição verdadeira do animal usado na avaliação não é o critério ideal. De acordo com NIELSEN et al. (1998), a elevada SE e a elevada SP do teste podem levar a erro de classificação de algumas amostras pelos testes usados como parâmetro, reduzindo o desempenho do teste que está sendo avaliado. Além do mais, variação nas estimativas de SE e SP é comumente observada entre diferentes estudos de validação de testes de diagnóstico (GREINER \& GARDNER, 2000). Segundo esses autores, essa variação é atribuída principalmente à população de referência e às estratégias de amostragem, além de erros aleatórios e sistemáticos.

$\mathrm{Na}$ comparação dos resultados do laboratório 1 com os dos laboratórios 2, 3 e 4, obtevese como indicador kappa, respectivamente, 0,69, 0,69 e 0,68 , o que significa que a concordância entre os resultados do laboratório 1 e os resultados dos outros laboratórios foi boa. Já a comparação entre os resultados dos laboratórios 2, 3 e 4 proporcionou kappa variando de 0,94 a 0,97 , demonstrando concordância excelente entre os resultados dos testes desses três laboratórios (Tabela 2). Os resultados obtidos nesses três laboratórios foram bastante parecidos, para a grande maioria dos soros examinados, porém apresentaram alguma discrepância em relação aos resultados do laboratório 1, discrepância associada a questões circunstanciais desse laboratório, sem relação com problemas da técnica em si, tais como seus reagentes, seu equipamento ou a conservação das amostras.

$\mathrm{Na}$ comparação dos resultados do laboratório 1 com os resultados dos laboratórios 2, $3 \mathrm{e}$ 4, os coeficientes de correlação de Pearson (r) observados foram, respectivamente, de: 0,$78 ; 0,77$; e 0,76 , indicando uma correlação moderada entre os resultados de mP encontrados. Já a comparação entre os resultados dos outros três laboratórios mostra coeficiente de correlação mais elevado: 0,99 entre os laboratórios 2 e 3, 0,96 entre os laboratórios 2 e 4, e 0,96 entre os laboratórios 3 e 4 , demonstrando a existência de uma forte relação linear positiva entre os resultados dos testes realizados por esses laboratórios. Isso significa que houve coerência nos resultados dos laboratórios (Tabela 2).

Os pares discordantes nos padrões-ouro, ou seja, animais com resultados divergentes nos testes do 2-ME e da RFC, estão ilustrados na tabela 3. Pelos valores da mediana de $\mathrm{mP}$ no soro de animais positivos no 2-ME (negativos na RFC) e positivos na RFC (negativos no 2-ME) e dos pontos de corte de cada laboratório, observa-se que aproximadamente $50 \%$ dos resultados no TPF correspondem aos resultados positivos em cada um dos comparativos. O restante significa que os testes estão discordando (Tabela 3).

Os resultados obtidos sugerem que o TPF, pelo desempenho apresentado, seria um recurso útil para o diagnóstico da brucelose bovina no Brasil, contribuindo para avanços no PNCEBT. Essa vantagem é mais acentuada ainda em áreas que, como o Brasil, adotam a vacinação com a amostra B19, fator reconhecido como causa frequente de resultados falso-positivos, uma vez que o teste é menos sujeito à influência de anticorpos vacinais, apresentando melhor especificidade que os testes convencionais para o diagnóstico em animais vacinados (NIELSEN et al., 1996). O teste é fácil, rápido e bastante confiável, quando realizado por pessoa devidamente treinada e cuidadosa, que observe os preceitos estabelecidos para sua execução. Uma desvantagem do TPF que não pode ser desprezada, especialmente em áreas carentes de recursos financeiros, é o custo do equipamento e dos reagentes, o que o torna mais caro que os testes adotados pelo PNCEBT, além da dependência de importação desses itens, embora haja circunstâncias que justificam o uso de um teste caro e de melhor desempenho.

Tabela 2 - Comparação entre os resultados do teste de polarização fluorescente obtidos nos quatro laboratórios (L), por meio do índice kappa (resultados dicotômicos) e do coeficiente de correlação (r, resultados contínuos).

\begin{tabular}{lcccccc}
\hline Indicador $^{1}$ & L1 x L2 & L1 x L3 & L1 x L4 & L2 x L3 & L2 x L4 & L3 x L4 \\
\hline Kappa & 0,69 & 0,69 & 0,68 & 0,97 & 0,95 & 0,94 \\
$\mathrm{r}$ & 0,78 & 0,77 & 0,76 & 0,99 & 0,96 & 0,96 \\
\hline
\end{tabular}

${ }^{1} \mathrm{P}<0,01$ 
Tabela 3 - Resultados do teste de polarização fluorescente (TPF), expressos em unidades de milipolarização (mP), em animais com resultados discordantes nos testes do mercaptoetanol (2-ME) e da reação de fixação do complemento (RFC). Os resultados positivos no 2-ME correspondem aos pares negativos na RFC e vice-versa.

\begin{tabular}{|c|c|c|c|c|c|c|c|}
\hline \multirow{3}{*}{ Laboratórios } & \multirow{3}{*}{ Ponto de corte TPF (mP) } & \multicolumn{6}{|c|}{---------------------------Valores em mP no TPF---------------------------------- } \\
\hline & & \multicolumn{3}{|c|}{------------2-ME Positivo-------------- } & \multicolumn{3}{|c|}{-------------RFC Positivo-------------- } \\
\hline & & Média & Mediana & Min. - Máx. & Média & Mediana & Min. - Máx. \\
\hline 1 & 88,9 & \multicolumn{3}{|c|}{$229,3^{1}$} & 87,3 & 72,1 & $66,6-246,9$ \\
\hline 2 & 93,6 & 115,4 & 96,1 & $66,1-295,1$ & 98,8 & 84,1 & $69,1-250,1$ \\
\hline 3 & 87,3 & 84,5 & 81,2 & $52,8-207,2$ & 98 & 86,9 & $70,5-212,9$ \\
\hline 4 & 88,2 & 121,8 & 84,1 & $61,4-470,4$ & 104,7 & 84,1 & $65,4-253,3$ \\
\hline
\end{tabular}

${ }^{1}$ Apenas um animal positivo discordante no teste do mercaptoetanol.

\section{CONCLUSÃO}

Os resultados do trabalho permitem concluir que o teste de polarização fluorescente apresentou alta sensibilidade, alta especificidade e alta reprodutibilidade interlaboratorial. Devido a esse bom desempenho, à facilidade e à rapidez de execução, o teste poderá ser útil ao programa de controle e erradicação em vigor no Brasil.

\section{AGRADECIMENTOS}

À Fundação de Amparo à Pesquisa do Estado de São Paulo (Fapesp), pelo auxílio financeiro.

\section{REFERÊNCIAS}

ALTON, G.G. et al. Techniques for the brucellosis laboratory. Paris: Institut National de la Recherche Agronomique, 1988. 190p.

BRASIL. Instrução Normativa n.6, de 08 de janeiro de 2004. Regulamento Técnico do Programa Nacional de Controle e Erradicação da Brucelose e Tuberculose Animal. Diário Oficial da República Federativa do Brasil, Poder Executivo, Brasília, DF, 12 de janeiro de 2004, seção 1, p.6-10.

BRASIL. Ministério da Agricultura, Pecuária e Abastecimento. Departamento de Defesa Animal. Programa Nacional de Controle e Erradicação de Brucelose e Tuberculose. Manual Técnico. 2006. 184p.

CHAPPEL, R.J. Diagnosis of bovine brucellosis: principles, practice and problems. Surveillance, v.16, p.3-6, 1989.

DAJER, A. et al. Evaluation of a fluorescence-polarization assay for the diagnosis of bovine brucellosis in México. Preventive Veterinary Medicine, v.40, p.67-73, 1999. Disponível em: <http://www.sciencedirect.com/ science?_ob=MImg\&_imagekey=B6T B K-3 WBNS 1 1-55\&_cdi=5145\&_user=972052 >. Acesso em 04 nov. 2009.

DOHOO, I. et al. Veterinary epidemiologic research. Charlottetown: AVC Inc., 2003. 706p.

GONÇALVES, V.S.P. et al. Situação epidemiológica da brucelose bovina no Estado de Minas Gerais. Arquivo Brasileiro de Medicina Veterinária e Zootecnia, v.61, supl.1, p.35-45,
2009. Disponível em: <http://www.scielo.br/pdf/abmvz/v61s1/ a06v61s1.pdf $>$. Acesso em: 15 abril 2010. doi: 10.1590/S010209352009000700003.

GREINER, M. et al. A modified ROC analysis for the selection of cut-off values and the definition of intermediate results of serodiagnostic tests. Journal of Immunological Methods, v.185, p.123-132, 1995. Disponível em: <http://

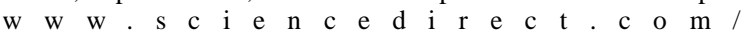
science?_ob=MImg\&_imagekey=B6T2Y-3Y 6PRCB-3X4\&_cdi=4931\&_user=972052 >. Acesso em 25 nov. 2009.

GREINER, M.; GARDNER, I.A. Epidemiologic issues in the validation of veterinary diagnostic tests. Preventive Veterinary Medicine, v.45, p.3-22, 2000. Disponível em: $<\mathrm{h} \mathrm{t} \mathrm{t} \mathrm{p} \mathrm{:} \mathrm{/} \mathrm{/} \mathrm{w} \mathrm{w} \mathrm{w.} \mathrm{s} \mathrm{c} \mathrm{i} \mathrm{e} \mathrm{n} \mathrm{c} \mathrm{e} \mathrm{d} \mathrm{i} \mathrm{r} \mathrm{e} \mathrm{c} \mathrm{t} \mathrm{.} \mathrm{c} \mathrm{o} \mathrm{m/}$ science?_ob=MImg\&_imagekey=B6TBK-408B JCN-2Y\&_cdi $=5145 \&$ \&user $=972052>$. Acesso em 25 nov. 2009.

LANDIS, J.R.; KOCH, G.G. The measurement of observer agreement for categorical data. Biometrics, v. 3, p.159-174, 1977.

MCGIVEN, J.A.et al. Validation of FPA and cELISA for the detection of antibodies to Brucella abortus in cattle and comparison to SAT, CFT, and iELISA. Journal of Immnological Methods, v.278, p.171178, 2003. Disponível em: <http://www.sciencedirect.com/ science?_ob=MImg\&_imagekey=B 6T2 Y-48MYG7R-17\&_cdi=4931\&_user=972052>. Acesso em 05 nov. 2009.

NIELSEN, K.; GALL, D. Fluorescence polarization assay for the diagnosis of brucellosis: a review. Journal of Immunoassay and Immunochemistry, v.22, p.183-201, 2001 .

NIELSEN, K. et al. A homogenous fluorescence polarization assay for detection of antibody to Brucella abortus. Journal of Immunological Methods, v.195, p.161-168, 1996. Disponível em: <http://www.sciencedirect.com/ science?_ob=MImg\&_imagekey=B 6T2Y-3W3169C-P2\&_cdi=4931\&_user=972052>. Acesso em 04 nov. 2009.

NIELSEN, K. et al. Diagnosis of bovine brucellosis using a homogeneous fluorescence polarization assay. Veterinary Immunology and Immunopathology, v.66, p.321-329, 1998. Disponível em: <http://www.sciencedirect.com/ science?_ob=MImg\&_imagekey=B6TD5-3 V92H KV-B 5\&_cdi=5189\&_user=972052 >. Acesso em 05 nov. 2009.

SAMARTINO, L. et al. Fluorescence polarization assay: application to the diagnosis of bovine brucellosis in Argentina. Journal of Immunoassay, v.20, p.115-126, 1999. 